Louisiana State University

LSU Digital Commons

$10-1-2014$

\title{
Comparison of infrapatellar and subcutaneous adipose tissue stromal vascular fraction and stromal/stem cells in osteoarthritic subjects
}

\author{
Pedro Pires de Carvalho \\ Pennington Biomedical Research Center \\ Katie M. Hamel \\ Pennington Biomedical Research Center \\ Robert Duarte \\ LSU Health Sciences Center - New Orleans \\ Andrew G.S. King \\ LSU Health Sciences Center - New Orleans \\ Masudul Haque \\ School of Veterinary Medicine
}

See next page for additional authors

Follow this and additional works at: https://digitalcommons.Isu.edu/biosci_pubs

\section{Recommended Citation}

Pires de Carvalho, P., Hamel, K., Duarte, R., King, A., Haque, M., Dietrich, M., Wu, X., Shah, F., Burk, D., Reis, R., Rood, J., Zhang, P., Lopez, M., Gimble, J., \& Dasa, V. (2014). Comparison of infrapatellar and subcutaneous adipose tissue stromal vascular fraction and stromal/stem cells in osteoarthritic subjects. Journal of Tissue Engineering and Regenerative Medicine, 8 (10), 757-762. https://doi.org/10.1002/ term. 1565

This Article is brought to you for free and open access by the Department of Biological Sciences at LSU Digital Commons. It has been accepted for inclusion in Faculty Publications by an authorized administrator of LSU Digital Commons. For more information, please contact ir@lsu.edu. 


\section{Authors}

Pedro Pires de Carvalho, Katie M. Hamel, Robert Duarte, Andrew G.S. King, Masudul Haque, Marilyn A.

Dietrich, Xiying Wu, Forum Shah, David Burk, Rui L. Reis, Jennifer Rood, Ping Zhang, Mandi Lopez, Jeffrey M. Gimble, and Vinod Dasa 


\title{
Comparison of infrapatellar and subcutaneous adipose tissue stromal vascular fraction and stromal/stem cells in osteoarthritic subjects
}

\author{
Pedro Pires de Carvalho ${ }^{1,2,3 \#}$, Katie M. Hamel ${ }^{1 \#}$, Robert Duarte ${ }^{4}$, Andrew G. S. King ${ }^{4}$, \\ Masudul Haque ${ }^{5}$, Marilyn A. Dietrich ${ }^{5}$, Xiying $\mathrm{Wu}^{1}$, Forum Shah ${ }^{1}$, David Burk ${ }^{1}$, Rui L. Reis ${ }^{2,3}$, \\ Jennifer Rood ${ }^{1}$, Ping Zhang ${ }^{4,6}$, Mandi Lopez ${ }^{4,5}$, Jeffrey M. Gimble ${ }^{1,4 *}$ and Vinod Dasa ${ }^{4}$ \\ ${ }^{1}$ Pennington Biomedical Research Center, 6400 Perkins Road, Baton Rouge, LA, USA \\ ${ }^{2} 3$ Bs Research Group, Biomaterials, Biodegradables and Biomimetics, University of Minho, Headquarters of the European Institute of \\ Excellence on Tissue Engineering and Regenerative Medicine, Avepark, Guimarães, Portugal \\ ${ }^{3}$ ICVS/3Bs PT Government Associated Laboratory, Braga/Guimarães, Portugal \\ ${ }^{4}$ Louisiana State University Health Sciences Center and Musculoskeletal Research Consortium, New Orleans, LA, USA \\ ${ }^{5}$ Louisiana State University School of Veterinary Medicine, Baton Rouge, LA, USA \\ ${ }^{6}$ Michigan State University, Department of Surgery, East Lansing, MI, USA
}

\begin{abstract}
Since inflammatory mechanisms have been postulated to link obesity to osteoarthritis, the current study evaluated the ratio of immune cells to multipotent stromal cells within the infrapatellar fat pad (IPFP) and subcutaneous adipose tissue (SQ) of the knee; each depot has potential as a source of regenerative cells. The immunophenotypes of stromal vascular fraction (SVF) and adipose-derived stem cells (ASCs) of the IPFP and SQ were determined in tissues from osteoarthritic subjects $(n=7)$ undergoing total knee replacement. Based on a subset of surface antigens, the immunophenotype of ASCs from SQ of OA subjects was not significantly different from that of relatively healthy and leaner subjects undergoing elective liposuction surgery. Flow-cytometry comparison of SVF cell populations in the IPFP of OA subjects resembled those within the subject's own matched SQ, with the exception of the endothelial marker $\mathrm{CD} 31^{+}$, which was significantly greater in cells from SQ. In the OA subjects, lower numbers of capillary-like structures and higher numbers of stromal and alkaline phosphatase colony-forming units in the IPFP vs SQ were consistent with this finding; however, ASCs from both depots in OA subjects exhibited comparable adipogenic and osteogenic differentiation potential. Thus, the IPFP contains an ASC and immune cell population similar to that of donor-matched SQ, making it an alternative ASC source for tissue regeneration. Further studies will be needed to determine whether IPFP immune cell infiltrates play an aetiological role in osteoarthritis equivalent to that shown in diabetes associated with obesity. Copyright (c) 2012 John Wiley \& Sons, Ltd.
\end{abstract}

Received 2 December 2011; Accepted 6 June 2012

Supporting information may be found in the online version of this article.

Keywords infrapatellar fat pad; subcutaneous adipose tissue; osteoarthritis; obesity; flow cytometry; immunophenotype

\section{Introduction}

Adipose tissue is widely distributed throughout the human body. It not only functions as an endocrine organ but also

*Correspondence to: Jeffrey M. Gimble, Pennington Biomedical Research Center, 6400 Perkins Road, Baton Rouge, LA, USA. E-mail: gimblejm@pbrc.edu

${ }^{\#}$ These authors contributed equally to this study. has anti-inflammatory and immunomodulatory characteristics. Secretion of trophic factors, such as adiponectin and leptin, by adipose tissue influences other hormonal pathways in the body. In addition to its secretory activity, adipose tissue plays a role in regulating energy metabolism as well as neuroendocrine and immune functions via a feedback loop with the central nervous system. The stromal vascular fraction (SVF), an isolated cell pellet obtained after enzymatic digestion and centrifugation of a tissue sample, 
contains multiple cell lineages, including pre-adipocytes, endothelial cells, mesenchymal stem cells (MSCs) and leukocytes. T cells, a subset of leukocytes, recognize specific antigens with a specific cell surface antigen $\mathrm{T}$ cell receptor (TCR) (Liossis and Tsokos, 1998). This recognition by T cells leads to the activation, proliferation and secretion of cytokines and growth factors. These $\mathrm{T}$ cell populations reside in adipose tissue and contribute to the systemic inflammation observed with obesity.

The infrapatellar or Hoffa's fat pad (IPFP) is an intracapsular, extrasynovial structure within the knee that lies directly posterior to the patellar tendon (Saddik et al., 2004). It is routinely removed during knee replacement surgery, and may serve as a unique source of ASCs from previously discarded tissue. Unlike subcutaneous adipose tissue (SQ), which is viewed primarily as an endocrine and metabolic depot, the infrapatellar fat pad has a unique role as a mechanical fat depot (Clockaerts et al., 2010). In addition to the degenerative changes throughout the knee, osteoarthritis (OA) affects the infrapatellar fat pad via inflammation mediated by $\mathrm{T}$ cell-induced cytokine cascades (Clockaerts et al., 2010). $\mathrm{T}$ cells are believed to play a significant role in the onset and progression of knee OA through pro-inflammatory cytokine release and subsequent activation of macrophage populations within adipose tissue (Sakkas and Platsoucas, 2007; Yang et al., 2010). The T cells interact with and activate several cell types, including macrophages, monocytes, chondrocytes and osteoclasts, through either soluble mediators or direct interaction. $\mathrm{T}$ cell activation can also contribute to joint destruction in OA by both inducing the production of collagenase, an enzyme responsible for cleaving peptide bonds in collagen, and triggering apoptosis of chondrocytes in the knee cartilage (Yang et al., 2010).

Inflammatory changes in adipose tissue are not limited to the IPFP. Peripheral and visceral adipose depots exhibit inflammatory changes in the context of metabolic syndrome, obesity and diabetes (Apovian et al., 2008; Kloting et al., 2010; Strissel et al., 2007; Weisberg et al., 2003; Xu et al., 2003). Adipose tissue from obese subjects displays an increased density of macrophages or 'crown' cells (Apovian et al., 2008; Kloting et al., 2010; Strissel et al., 2007; Weisberg et al., 2003; Xu et al., 2003), as well as distinct $\mathrm{T}$ cell populations relative to lean individuals (Feuerer et al., 2009; Nishimura et al., 2009; Duffaut et al., 2009b; Winer et al., 2009; Yang et al., 2010). A growing body of literature supports a role for $\mathrm{T}$ cell-derived cytokines as causative agents in the onset and progression of metabolic syndrome locally within the adipose tissue (Duffaut et al., 2009a, 2009b; Yang et al., 2010).

We therefore asked: (a) whether osteoarthritis alters the subcutaneous adipose cell population as compared to a relatively healthy subject undergoing elective liposuction; and (b) whether the IPFP from osteoarthritic subjects would exhibit cell populations similar to that of donor-matched subcutaneous adipose tissue. To address these questions, the immunophenotype of the SVF cells and adherent, culture-expanded adipose-derived stromal/stem cells (ASCs) isolated from the IPFP and subcutaneous adipose tissue of patients undergoing total knee replacement were compared to each other and to liposuction aspirates from healthy individuals.

\section{Methods}

\subsection{Institutional review board and patient evaluation}

All specimens were collected under protocols reviewed and approved by institutional review boards at the Louisiana State University School of Medicine-New Orleans (LSUHSC-NO; Protocol No. 7248) and the Pennington Biomedical Research Center (PBRC; Protocols Nos 10007 and 23040). Studies were conducted in accordance with the 1964 Declaration of Helsinki and with US HIPAA requirements. Patients undergoing total knee replacement were evaluated with respect to their medical history and physical examination for evidence of diabetes and metabolic disease, hypertension and osteoarthritis. Radiological evaluation was used to grade for the Kellgren-Lawrence score, which measures joint narrowing, osteophyte formation and deformity of bone contours (Kellgren and Lawrence, 1957).

\subsection{Serum analysis}

Blood serum samples were collected from osteoarthritic subjects undergoing elective knee replacement $(n=9)$ or from subjects undergoing elective liposuction or bariatric surgery $(n=30)$ and transported to the clinical chemistry laboratory at PBRC for further analysis (Table 1). Of the osteoarthritic subjects, $33 \%$ of the donors were diabetic and $66 \%$ were hypertensive. The Homeostasis Model of Assessment Insulin Resistance (HOMA-IR) was calculated as follows: fasting insulin $(\mu \mathrm{U} / \mathrm{ml}) \times$ fasting glucose $(\mathrm{mg} / \mathrm{dl}) / 405$. All blood samples were collected from fasting glucose levels.

\subsection{SVF cells and ASCs isolation and expansion}

The samples were transported to Pennington Biomedical on the day of the procedure. Infrapatellar fat pad, periarticular

Table 1. Donor demographics and serum analysis data

\begin{tabular}{lccl}
\hline Subjects & OA & Controls & $p$ \\
\hline Donor number & 9 & 30 & \\
Donor age & $64.4 \pm 18.0$ & $43.8 \pm 11.1$ & 0.09 \\
BMl & $34.3 \pm 8.7$ & $25.8 \pm 3.9$ & 0.019 \\
Kellergen-Lawrence score & $3.4 \pm 1.2$ & ND & \\
Glucose $(\mathrm{mg} / \mathrm{dl})$ & $113.6 \pm 21.0$ & $79.6 \pm 17.7$ & 0.001 \\
Cholesterol $(\mathrm{mg} / \mathrm{dl})$ & $161.3 \pm 21.0$ & $179.1 \pm 29.6$ & 0.275 \\
HDL $(\mathrm{mg} / \mathrm{dl})$ & $46.1 \pm 15.7$ & $59.2 \pm 12.9$ & 0.042 \\
LDL $(\mathrm{mg} / \mathrm{dl})$ & $90.8 \pm 27.6$ & $101.3 \pm 25.0$ & 0.328 \\
HOMA-IR & $3.0 \pm 2.9$ & $1.0 \pm 1.6$ & 0.076 \\
Insulin $(\mu \mathrm{U} / \mathrm{ml})$ & $9.8 \pm 6.8$ & $4.9 \pm 7.5$ & 0.085 \\
Triglyceride $(\mathrm{mg} / \mathrm{dl})$ & $122.3 \pm 43.1$ & $93.1 \pm 45.6$ & 0.102 \\
\hline
\end{tabular}

ND, not done; OA, osteoarthritis. 
subcutaneous adipose tissue and blood serum samples were collected from osteoarthritic subjects ( $n=9$ total for serum analysis, $n=6-7$ used in cell culture and flow-cytometry data analysis) undergoing total knee replacement. After weighing, the IPFP and SQ samples were minced, washed two or three times with phosphate-buffered saline (PBS) and digested in a volume of $2 \mathrm{ml}$ collagenase digest: $1 \mathrm{~g}$ tissue ( $20 \mathrm{ml}$ PBS, $20 \mu \mathrm{l} 2 \mathrm{~mm}$ calcium chloride, $20 \mathrm{mg}$ collagenase, $200 \mathrm{mg}$ albumin) in a rocker dry oven at $37^{\circ} \mathrm{C}$ for $1 \mathrm{~h}$. Following digestion, the samples were centrifuged twice at $300 \times g$ for $5 \mathrm{~min}$, filtered using a $100 \mu \mathrm{M}$ filter and centrifuged again at $300 \times g$ for $5 \mathrm{~min}$ to obtain the SVF. In order to remove erythrocytes from the sample and decrease the total number of events in flow-cytometry analysis, $5 \mathrm{ml}$ red blood cell lysis buffer (200 ml distilled water, $1.66 \mathrm{~g}$ ammonium chloride, $0.2 \mathrm{~g}$ potassium bicarbonate, $0.605 \mu 10.25 \mathrm{M}$ EDTA) was used; $20 \mathrm{ml}$ PBS was added to terminate RBC lysis. After centrifugation at $300 \times g$ for $5 \mathrm{~min}$, the supernatent was removed and the samples were resuspended in $5 \mathrm{ml}$ stromal medium [DMEM/F-12, 10\% fetal bovine serum (FBS; Hyclone, Logan, UT, USA), 1\% antibiotic/antimycotic (MP Biomedicals, Solon, OH, USA)]. Following the processing procedure, $20 \mu \mathrm{l}$ cell suspension from both samples was stained with trypan blue (Sigma-Aldrich, St. Louis, MO, USA) and counted using a haemocytometer. Cells from IPFP $(n=7)$ and SQ $(n=6)$ obtained from osteoarthritic subjects or subcutaneous lipoaspirate samples $(n=3)$ from patients undergoing elective cosmetic surgery were expanded and differentiated along the adipocyte and osteoblast pathways as previously described (Yu et al., 2010). Additionally, fibroblast (CFU-F) and osteoblast (CFU-ALP) colonyforming unit assays were performed in six-well plates, where individual wells were seeded with 50 or 100 passage 1 ASCs from IPFP or SQ from osteoarthritic subjects, as previously described (Staszkiewicz et al., 2010).

\subsection{Flow cytometry}

Flow-cytometry analysis (LSRII from BD Biosciences, San Jose, CA, USA) was performed according to published protocols (Yu et al., 2010). The SVF cells were analysed immediately following the initial collagenase digestion procedure, while the passage 2 ASCs were analysed following culture expansion and trypsin release; no cells were cryopreserved prior to analysis. If necessary, the samples were diluted to the required concentration of $1 \times 10^{6}$ cells $/ \mathrm{ml}$. The cells were washed in $10 \mathrm{ml}$ PBS and centrifuged twice at $300 \times g$ for $5 \mathrm{~min}$, then resuspended in $500 \mu \mathrm{l}$ cold PBS. The sample was transferred to a $1.5 \mathrm{ml}$ microcentrifuge tube containing the $87 \mu \mathrm{l}$ mixture of the 13-fluorochrome panel (see Supporting information, Table S1). The stained samples were incubated in a dark environment at room temperature for $30 \mathrm{~min}$. The cells were then washed with $1 \mathrm{ml}$ PBS and 1\% BSA and centrifuged at $300 \times g$ for $3 \mathrm{~min}$, three times. They were resuspended in $500 \mu \mathrm{l} 1 \%$ formaldehyde in PBS, stored at $4{ }^{\circ} \mathrm{C}$, and transported to LSUHSC-NO within $48 \mathrm{~h}$ for flow-cytometry analysis.

\subsection{Endothelial cell labelling}

A 100-200 mg piece of tissue was sectioned from subcutaneous adipose tissue and infrapatellar fat pad samples $(n=3)$ and transferred to a $1.5 \mathrm{ml}$ microcentrifuge tube; $1 \mathrm{ml}$ stock solution of isolectin $(500 \mathrm{mg} / \mathrm{ml})$ was diluted to $10 \mu \mathrm{g} / \mathrm{ml}$ and transferred to each sample. The sections were then incubated in the dark for $1 \mathrm{~h}$ with lectin fluorescein isothiocyanate (FITC) conjugate from Ulex europaeus (Sigma-Aldrich) (Pasarica et al., 2009). Samples were then washed with PBS and analysed using a confocal microscope. Vessel density was determined by superimposing an image of each sample on a grid, using ImageJ software. Vessel density was defined as the number of times a vessel intersects a gridline within the specified area.

\subsection{Statistics}

Values are expressed as mean \pm standard deviation (SD), where statistical significance is determined by $p$ values 0.05 , based on Student's $t$-test.

\section{Results and discussion}

Adipose tissue presents an accessible and abundant source of adult stromal/stem cells for regenerative medical therapies (Gimble et al., 2007). The majority of data on human SVF cells and ASCs is from subcutaneous adipose tissue isolated from relatively young and healthy subjects undergoing elective liposuction surgery (Aust et al., 2004; Gimble et al., 2007; Gronthos et al., 2001; McIntosh et al., 2006; Mitchell et al., 2006; Yu et al., 2010; Zuk et al., 2002); however, evaluation of cells isolated from subcutaneous adipose tissue of osteoarthritic subjects is limited at best. Therefore, the first research question was addressed by initial studies comparing the demographics, serum profile and SVF immunophenotype between osteoarthritic patients undergoing knee replacement and healthy elective liposuction subjects (Table 1; see also Supporting information, Table S2). The osteoarthritic population was significantly older than the healthy control population (mean age 64.4 vs 43.8 years). With one exception, all knee replacement patients were overweight or obese, with a mean BMI of 34.3 (range 22.3-53.8), significantly greater than that of the controls (mean BMI 25.8, range 20.9-34.5). Consistent with the fact that $33 \%$ of osteoarthritic subjects were diabetic, their fasting glucose levels were significantly elevated relative to controls, with a trend towards increased triglyceride levels, insulin levels and HOMA-IR, a derived value reflecting the level of insulin sensitivity. While HDL levels were significantly higher in the control relative to the osteoarthritic cohort, cholesterol and LDL levels were comparable. The knee replacement cohort displayed a mean Kellgren-Lawrence score of 3.4 ; this 
parameter was not evaluated in the liposuction cohort. The immunophenotype of the stromal vascular fraction (SVF) cells obtained from subcutaneous lipoaspirate samples donated by healthy liposuction subjects $(n=3)$ was similar to that from SQ of osteoarthritic knees, based on expression of a limited panel of endothelial (CD31), lymphoid (CD16, CD56), myeloid (CD14) and stromal (CD29) surface antigens (see Supporting information, Table S2). Although the current study examined only three liposuction donors in detail, the data obtained within this limited cohort were consistent with our own previously published studies (with $n=5-7$ up to $n=64$ subjects) (Aust et al., 2004; Gronthos et al., 2001; McIntosh et al., 2006; Mitchell et al., 2006; Yu et al., 2010) as well as that of others in the field (Katz et al., 2005; Maumus et al., 2011; Zuk et al., 2002). These data support the conclusion that subcutaneous adipose tissue has a similar potential as a stromal/stem cell source, independent of whether it is obtained from older, more obese osteoarthritic subjects with a higher incidence of diabetes or younger, leaner liposuction donors with no history of metabolic disease.

A number of studies in the literature have evaluated the differentiation potential and immunophenotype of ASCs isolated from the IPFP (Buckley et al., 2010a, 2010b; Dragoo et al., 2003; Khan et al., 2008, 2009, 2010; Wickham et al., 2003); however, only one study has performed a side-by-side comparison between these cells and bone marrow-derived MSCs (Vinardell et al., 2011) and none has compared them to subcutaneous adiposederived ASCs. Therefore, the SVF cells and ASCs from matched IPFP and SQ adipose tissue from osteoarthritic subjects were compared in the second experiment of the current study. Flow-cytometric analyses were performed on the freshly isolated SVF cells from both depots, prior to plastic adherence or culture expansion using a wide panel of antibodies for lineage-specific antigens (Tables 2A and $2 \mathrm{~B}$ ). Compared to the IPFP, SQ SVF cells displayed significantly increased expression of the endothelial cell marker CD31 $(p=0.02)$, while other B cell (CD20), memory/effector/regulatory T cell (CD3, 4, 8, 25), myeloid (CD14), natural killer cell (CD56, CD66) and mesenchymal (CD29) antigens were comparable (Tables 2A and 2B; see also Supporting information, Figure S1, Table S2). Flow cytometry of trypsin-harvested passage 2 ASCs showed that the immunophenotype was not significantly different between matched IPFP and SQ depots of osteoarthritic donors for expression of haematopoietic (CD34, CD45) and stromal (CD29, CD44, CD73, CD90, CD105) antigens (see Supporting information, Table S2). Values were consistent with previous characterizations of passaged human ASCs from subcutaneous depots of healthy donors undergoing elective liposuction surgery (Gronthos et al., 2001; McIntosh et al., 2006; Mitchell et al., 2006; Yu et al., 2010).

Sakkas and Platsoucas (2007) and Sakkas et al. (1998) found $\mathrm{T}$ cell aggregates in $65 \%$ of patients with $\mathrm{OA}$, and the T cells contribute to OA progression through release of cytokines such as interferon- $\gamma$ and interleukin 2 . The current study confirms and extends this finding, documenting the presence of a significant percentage of $\mathrm{T}$ cells within the
Table 2A. Comparison of the stromal vascular fraction cell immunophenotype in matched infrapatellar fat pad and subcutaneous adipose tissue obtained from subjects undergoing total knee replacement

\begin{tabular}{llcc}
\hline Depot & \multicolumn{1}{c}{ Marker } & Mean & $p$ \\
\hline Subcutaneous & CD14 \%Parent & $22.9 \pm 8.2$ & 0.39 \\
fat pad & CD14 \%Parent & $17.9 \pm 13.6$ & \\
Subcutaneous & CD29+ \%Parent & $42.6 \pm 20$ & 0.27 \\
fat pad & CD29+ \%Parent & $34.1 \pm 30.2$ & \\
Subcutaneous & CD31 \%Parent & $22.3 \pm 7.8$ & 0.02 \\
fat pad & CD31 \%Parent & $9.9 \pm 5.1$ & \\
Subcutaneous & CD56 \%Parent & $16.2 \pm 12.1$ & 0.29 \\
fat pad & CD56 \%Parent & $7.2 \pm 10.8$ & \\
Subcutaneous & CD3 \%Parent & $11.8 \pm 9.6$ & 0.28 \\
fat pad & CD3 \%Parent & $6.6 \pm 4.5$ & \\
Subcutaneous & CD3 CD8 \% \%arent & $12.8 \pm 13.7$ & 0.64 \\
fat pad & CD3 ${ }^{+}$CD8 $\%$ Parent & $10.7 \pm 13.1$ & \\
Subcutaneous & CD16 \%Parent & $12.8 \pm 9.6$ & 0.50 \\
fat pad & CD16 \%Parent & $8.6 \pm 13.9$ & \\
Subcutaneous & CD66 \%Parent & $6.6 \pm 12$ & 0.25 \\
fat pad & CD66 \%Parent & $0.4 \pm 0.3$ & \\
Subcutaneous & CD20 \%Parent & $0.8 \pm 1.7$ & 0.32 \\
fat pad & CD20 \%Parent & $0.2 \pm 0.4$ & \\
\hline
\end{tabular}

Table 2B. Comparison of stromal vascular fraction immunophenotypes in subcutaneous adipose tissue obtained from subjects undergoing elective cosmetic surgery (lipoaspirate) or total knee replacement (subcutaneous)

\begin{tabular}{|c|c|c|c|}
\hline Sample & Marker & Mean & $p$ \\
\hline Lipoaspirate & CD14 \%Parent & $26.1 \pm 11.8$ & 0.60 \\
\hline Subcutaneous & CD14 \%Parent & $22.1 \pm 10.4$ & \\
\hline Lipoaspirate & CD16 \%Parent & $8.9 \pm 4.4$ & 0.83 \\
\hline Subcutaneous & CD16 \%Parent & $10.7 \pm 11.5$ & \\
\hline Lipoaspirate & CD56 \%Parent & $8.8 \pm 6.9$ & 0.16 \\
\hline Subcutaneous & CD56 \%Parent & $20.2 \pm 13.0$ & \\
\hline Lipoaspirate & CD31 \%Parent & $26.7 \pm 13.4$ & 0.52 \\
\hline Subcutaneous & CD31 \%Parent & $20.7 \pm 5.6$ & \\
\hline Lipoaspirate & CD29 ${ }^{+} \%$ Parent & $45.8 \pm 19.8$ & 0.41 \\
\hline Subcutaneous & $\mathrm{CD} 9^{+} \%$ Parent & $31.9 \pm 13.8$ & \\
\hline
\end{tabular}

IPFP stromal vascular fraction, where $\mathrm{CD} 3^{+} \mathrm{CD} 8^{+} \mathrm{T}$ cells accounted for $\sim 11 \%$ of the total population. With respect to lymphoid and myeloid cell markers, the composition of the IPFP was not significantly different from that of matched subcutaneous adipose tissue. While this suggests that the local microenvironments are comparable with respect to inflammation in both depots, additional evaluation of cytokines and inflammatory biomarkers should be evaluated in future comparisons of matched tissues.

Colony-forming unit assays compared passage 1 cells from matched IPFP and SQ depots ( $n=6$ donors) cultured under osteogenic (CFU-ALP) or undifferentiated conditions (CFU-F) (Figure 1 and Table 3). The CFU-F and CFU-ALP frequencies were significantly greater by 1.33 -fold and 1.37-fold, respectively, in the IPFP relative to subcutaneous adipose tissue. Confocal photomicrographs of the lectinstained adipose tissues examined vascularization of subcutaneous adipose tissue relative to the IPFP (Figure S4). Image analyses indicated that subcutaneous adipose tissue exhibited $22 \%$ more vessel intersections than IPFP $(75.7 \pm 12.1$ vs $62.3 \pm 14.6, n=3$ donors); however, these findings did not achieve significance ( $p=0.239$, one-tailed $t$-test). The ASCs 


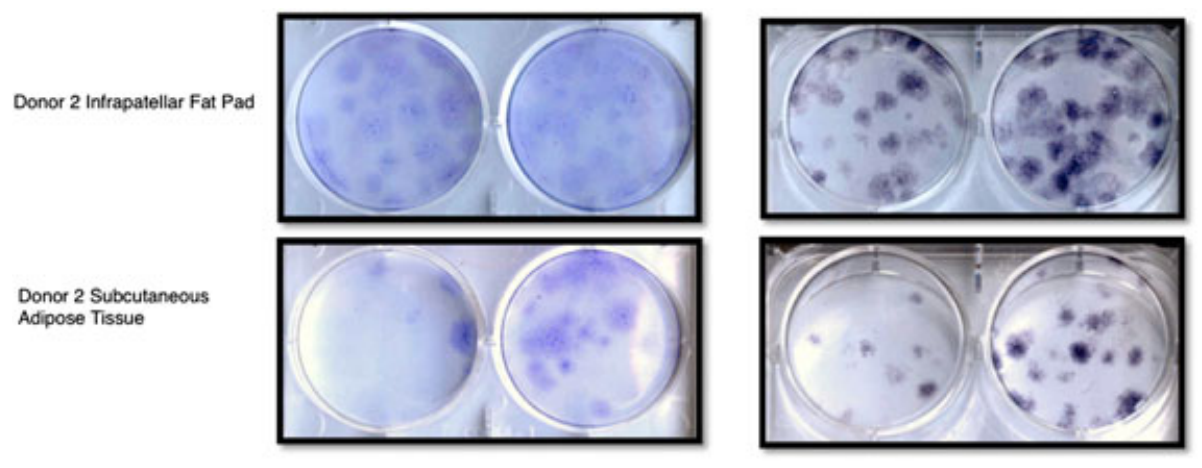

Figure 1. Colony-forming unit (CFU) assay and staining. IPFP and subcutaneous adipose tissue samples were diluted to concentrations of 50 (left wells) or 100 (right wells) cells $/ \mathrm{ml}$ and plated in six-well plates. After 7 days in culture, the wells were either maintained in stromal medium (CFU-F, left panel) or induced with osteoblast differentiation medium (CFU-ALP, right panel). After 9 days of induction, the colonies were stained with toluidine blue (CFU-F) or alkaline phosphatase (CFU-ALP)

Table 3. Comparative analysis of colony-forming unit frequency in infrapatellar fat pad and subcutaneous adipose tissue

\begin{tabular}{lccc}
\hline Tissue/CFU & CFU-F & CFU-ALP & $p$ \\
\hline IPFD & $23.3 \pm 4.9$ & $25.7 \pm 8.4$ & $4 \times 10^{-4}$ \\
SQ & $17.5 \pm 3.9$ & $18.8 \pm 6.0$ & $3 \times 10^{-3}$ \\
\hline
\end{tabular}

The colony forming unit-fibroblast (CFU-F) and alkaline phosphatase ${ }^{+}$ (CFU-ALP) were determined for 100 passage 1 ASCs from infrapatellar fat pad (IPFD) and subcutaneous (SQ) adipose tissue obtained from $n=6$ donors. Values are expressed as the mean \pm SD. $p$ values were determined based on Student's $t$-test; no significant difference $(p<0.05)$ was determined between CFU-F and CFU-ALP values in a single tissue (IPFD, SQ).

from both depots differentiated along adipocyte and osteoblast lineages, based on oil red $\mathrm{O}$ or alizarin red histochemical staining (see Supporting information, Figure S2), confirming previous reports on the differentiation potential of IPFP- and subcutaneous-derived ASCs (Dragoo et al., 2003; Khan et al., 2008; Wickham et al., 2003; Yu et al., 2010).

We recognize certain limitations of this study. Ideally, IPFP samples from the patients undergoing lipoaspiration would have been the best control. However, harvesting this tissue would have been unethical. Second, increased sample size would allow for greater differentiation between cohorts and control for various disease states. Additionally, to obtain clinically relevant numbers of cells, the IPFP ASCs must be cultured beyond the current level of passage 2 . While prior studies from our laboratory have examined subcutaneous ASCs from lipoaspirates up to passage 30, studies with IPFP at extended passages are needed (Izadpanah et al., 2006). Third, we did not compare the circulating systemic and tissue-specific adipokine profiles in matched IPFP and subcutaneous specimens. Nevertheless, these findings support the conclusion that the infrapatellar fat pad provides a potential source of ASCs for tissue engineering and regenerative medical applications comparable to that of subcutaneous adipose tissue (Dragoo et al., 2003; Khan et al., 2008; Wickham et al., 2003). The ASCs from both adipose depots are multipotent, capable of differentiating along the adipocyte and osteoblast lineage pathways. Likewise, the IPFP ASCs display an immunophenotype that is not significantly different from that of ASCs derived from donor-matched subcutaneous adipose tissue. The current data confirm and extend published studies documenting the multiple lineage differentiation potential of IPFPderived ASCs (Dragoo et al., 2003; Erickson et al., 2002; Guilak et al., 2006; Halvorsen et al., 2001; Khan et al., 2008; Wickham et al., 2003; Zuk et al., 2001, 2002). With the growth of total knee replacements estimated to reach 3.5 million surgeries by 2030, the IPFP may serve as a safe, low-cost and unique ASCs source for orthopaedic procedures (Kurtz et al., 2007).

\section{Acknowledgements}

We thank Dr James W. Wade, his staff and patients for providing samples for the study; members of the Stem Cell Biology Laboratory and Clinical Chemistry Core Facility at PBRC; and Constance Porretta at the LSU Health Science Center Flow Cytometry Shared Resource for performing analysis of the stromal vascular fractions. This project was funded by LSU Health Sciences Center Departments of Orthopaedics and Medicine and the Pennington Biomedical Research Foundation.

\section{Supporting information on the internet}

The following supporting information may be found in the online version of this article:

Figure S1. (A, B) Subcutaneous adipose tissue and infrapatellar fat pad flow cytometric histograms for panel of surface antigens

Figure S2. Flow-cytometry analysis of IPFP in comparison to subcutaneous adipose tissue

Figure S3. ASCs differentiation and staining

Figure S4. Lectin staining of intact adipose tissue

Table S1. FACS staining fluorochrome panel

Table S2. Comparison of passage 2 ASCs marker expression of the infrapatellar fat pad and subcutaneous adipose tissue 


\section{References}

Apovian CM, Bigornia S, Mott M, et al. 2008; Adipose macrophage infiltration is associated with insulin resistance and vascular endothelial dysfunction in obese subjects. Arterioscler Thromb Vasc Biol 28(9): 1654-1659.

Aust L, Devlin B, Foster SJ, et al. 2004; Yield of human adipose-derived adult stem cells from liposuction aspirates. Cytotherapy 6 (1): 7-14.

Buckley CT, Vinardell T, Kelly DJ. 2010a; Oxygen tension differentially regulates the functional properties of cartilaginous tissues engineered from infrapatellar fat pad derived MSCs and articular chondrocytes. Osteoarthr Cartilage 18(10): 1345-1354.

Buckley CT, Vinardell T, Thorpe SD, et al. 2010b; Functional properties of cartilaginous tissues engineered from infrapatellar fat pad-derived mesenchymal stem cells. J Biomech 43(5): 920-926.

Clockaerts S, Bastiaansen-Jenniskens YM, Runhaar J, et al. 2010; The infrapatellar fat pad should be considered as an active osteoarthritic joint tissue: a narrative review. Osteoarthr Cartilage 18(7): 876-882.

Dragoo JL, Samimi B, Zhu M, et al. 2003; Tissue-engineered cartilage and bone using stem cells from human infrapatellar fat pads. J Bone Joint Surg Br 85(5): 740-747.

Duffaut C, Galitzky J, Lafontan M, et al. 2009a; Unexpected trafficking of immune cells within the adipose tissue during the onset of obesity. Biochem Biophys Res Commun 384(4): 482-485.

Duffaut C, Zakaroff-Girard A, Bourlier V, et al. 2009b; Interplay between human adipocytes and T lymphocytes in obesity. CCL20 as an adipochemokine and $\mathrm{T}$ lymphocytes as lipogenic modulators. Arterioscler Thromb Vasc Biol 29(10): 1608-1614.

Erickson GR, Gimble JM, Franklin DM, et al. 2002; Chondrogenic potential of adipose tissue-derived stromal cells in vitro and in vivo. Biochem Biophys Res Commun 290 (2): 763-769.

Feuerer M, Herrero L, Cipolletta D, et al. 2009; Lean, but not obese, fat is enriched for a unique population of regulatory $\mathrm{T}$ cells that affect metabolic parameters. Nat Med 15(8): 930-939.

Gimble JM, Katz AJ, Bunnell BA. 2007; Adiposederived stem cells for regenerative medicine. Circ Res 100(9): 1249-1260.

Gronthos S, Franklin DM, Leddy HA, et al. 2001; Surface protein characterization of human adipose tissue-derived stromal cells. J Cell Physiol 189(1): 54-63.

Guilak F, Lott KE, Awad HA, et al. 2006; Clonal analysis of the differentiation potential of human adipose-derived adult stem cells. $J$ Cell Physiol 206(1): 229-237.

Halvorsen YD, Franklin D, Bond AL, et al. 2001; Extracellular matrix mineralization and osteoblast gene expression by human adipose tissue-derived stromal cells. Tissue Eng 7(6): 729-741.

Izadpanah R, Trygg C, Patel B, et al. 2006; Biologic properties of mesenchymal stem cells derived from bone marrow and adipose tissue. J Cell Biochem 99: 1286-1297. Katz AJ, Tholpady A, Tholpady SS, et al. 2005; Cell surface and transcriptional characterization of human adiposederived adherent stromal (hADAS) cells. Stem Cells 23(3): 412-423.

Kellgren JH, Lawrence JS. 1957; Radiological assessment of osteoarthrosis. Ann Rheum Dis 16(4): 494-502.

Khan WS, Adesida AB, Tew SR, et al. 2009, The epitope characterisation and the osteogenic differentiation potential of human fat pad-derived stem cells is maintained with ageing in later life. Injury 40(2): 150-157.

Khan WS, Johnson DS, Hardingham TE. 2010; The potential of stem cells in the treatment of knee cartilage defects. Knee 17(6): 369-374.

Khan WS, Tew SR, Adesida AB, et al. 2008; Human infrapatellar fat pad-derived stem cells express the pericyte marker 3G5 and show enhanced chondrogenesis after expansion in fibroblast growth factor-2. Arthritis Res Ther 10(4): R74.

Kloting N, Fasshauer M, Dietrich A, et al. 2010; Insulin-sensitive obesity. Am J Physiol Endocrinol Metab 299(3): E506-E515.

Kurtz S, Ong K, Lau E, et al. 2007; Projections of primary and revision hip and knee arthroplasty in the United States from 2005 to 2030. J Bone Joint Surg Am 89 (4): 780-785

Liossis SN, Tsokos GC. 1998; Cellular immunity in osteoarthritis: novel concepts for an old disease. Clin Diagn Lab Immunol 5 (4): 427-429.

Maumus M, Peyrafitte JA, D'Angelo R, et al. 2011; Native human adipose stromal cells: localization, morphology and phenotype. Int $J$ Obes (Lond) 35(9): 1141-1153.

McIntosh K, Zvonic S, Garrett S, et al. 2006; The immunogenicity of human adipose derived cells: temporal changes in vitro. Stem Cells 24: 1245-1253.

Mitchell JB, McIntosh K, Zvonic S, et al. 2006; The immunophenotype of human adipose derived cells: temporal changes in stromal- and stem cell-associated markers. Stem Cells 24: 376-385.

Nishimura S, Manabe I, Nagasaki M, et al. 2009; $\mathrm{CD}^{+}$effector $\mathrm{T}$ cells contribute to macrophage recruitment and adipose tissue inflammation in obesity. Nat Med 15(8): 914-920.

Pasarica M, Gowronska-Kozak B, Burk D, et al. 2009; Adipose tissue collagen VI in obesity. $J$ Clin Endocrinol Metab 94(12): 5155-5162.
Saddik D, McNally EG, Richardson M. 2004; MRI of Hoffa's fat pad. Skel Radiol 33(8): 433-444.

Sakkas LI, Platsoucas CD. 2007; The role of T cells in the pathogenesis of osteoarthritis. Arthritis Rheum 56(2): 409-424.

Sakkas LI, Scanzello C, Johanson N, et al. 1998; T cells and T cell cytokine transcripts in the synovial membrane in patients with osteoarthritis. Clin Diagn Lab Immunol 5 (4): 430-437.

Staszkiewicz J, Frazier TP, Rowan BG, et al. 2010; Cell growth characteristics, differentiation frequency, and immunophenotype of adult ear mesenchymal stem cells. Stem Cells Dev 19(1): 83-92.

Strissel KJ, Stancheva Z, Miyoshi H, et al. 2007; Adipocyte death, adipose tissue remodeling, and obesity complications. Diabetes 56(12): 2910-2918.

Vinardell T, Buckley CT, Thorpe SD, et al. 2011; Composition-function relations of cartilaginous tissues engineered from chondrocytes and mesenchymal stem cells isolated from bone marrow and infrapatellar fat pad. $J$ Tissue Eng Regen Med 5(9): 673-683.

Weisberg SP, McCann D, Desai M, et al. 2003; Obesity is associated with macrophage accumulation in adipose tissue. $J$ Clin Invest 112(12): 1796-1808.

Wickham MQ, Erickson GR, Gimble JM, et al. 2003; Multipotent stromal cells derived from the infrapatellar fat pad of the knee. Clin Orthop Relat Res 412: 196-212.

Winer S, Chan Y, Paltser G, et al. 2009; Normalization of obesity-associated insulin resistance through immunotherapy. Nat Med 15(8): 921-929.

Xu H, Barnes GT, Yang Q, et al. 2003; Chronic inflammation in fat plays a crucial role in the development of obesity-related insulin resistance. J Clin Invest 112(12): 1821-1830.

Yang $\mathrm{H}$, Youm $\mathrm{YH}$, Vandanmagsar $\mathrm{B}$, et al. 2010; Obesity increases the production of proinflammatory mediators from adipose tissue $\mathrm{T}$ cells and compromises TCR repertoire diversity: implications for systemic inflammation and insulin resistance. $J$ Immunol 185(3): 1836-1845.

Yu G, Wu X, Dietrich MA, et al. 2010; Yield and characterization of subcutaneous human adipose-derived stem cells by flow cytometric and adipogenic mRNA analyses. Cytotherapy 12: 538-546.

Zuk PA, Zhu M, Ashjian P, et al. 2002; Human adipose tissue is a source of multipotent stem cells. Mol Biol Cell $\mathbf{1 3}$ (12): 4279-4295.

Zuk PA, Zhu M, Mizuno $\mathrm{H}$, et al. 2001; Multilineage cells from human adipose tissue: implications for cell-based therapies. Tissue Eng 7(2): 211-228. 